\title{
Nasal Anthropometry and the Validity of Neoclassical Nasal Canons in Adult Ibibios
}

\author{
Dr. Antai, Margaret Sylvester ${ }^{*}$ \\ Department of Surgery, Plastic and Reconstructive Surgery Unit, University of Uyo Teaching Hospital, Uyo- Akwa Ibom State
}

\begin{tabular}{ll}
\hline DOI: $10.36348 /$ sjmps.2019.v05i11.015 & | Received: 11.11 .2019 | Accepted: $18.11 .2019 \mid$ Published: 29.11 .2019 \\
*Corresponding author: Dr. Antai, Margaret Sylvester &
\end{tabular}

*Corresponding author: Dr. Antai, Margaret Sylvester

\section{Abstract}

The nose is the central element of the face and has well defined racial, sexual and environmental characteristics and differences. Anthropometric analysis in the context of each patient's ethnic heritage forms the basis of an excellent result in rhinoplasty. Caucasian parameters have served as endpoints for nasal aesthetic and reconstructive surgery for centuries. As more non-Caucasians seek these surgeries, it has become evident that using a set of parameters cannot account for the great variability noted in people especially Africans. The objective of this study was to develop a reference for Ibibio nasal parameters which will guide reconstructive and aesthetic surgery and compare this with other ethnic groups in Nigeria and with other races. This was a prospective cross sectional community based study involving 200 males and 200 females aged 18-60 years, of Ibibio ethnic group in Akwa Ibom State, with no facial anomalies or history of facial surgery. Measurements were made with digital calipers and goniometers. Data were analyzed with SPSS version 20, independent t-test used to assess sexual dimorphism with significance level of $\mathrm{p}<0.05$. The nasal parameters assessed for males and females were: Nasal length $(46.4 \pm 1.7 \mathrm{~mm}$ and $46.1 \pm 1.6 \mathrm{~mm})$, Nasal width $(44.1 \pm 1.6 \mathrm{~mm}$ and 41.2 $\pm 1.3 \mathrm{~mm})$, Nasal index (95.2 \pm 3.2 and 89.6 \pm 3.4$)$, Ear length/Nasal length ( $0.8 \pm 0.5$ and $0.8 \pm 0.1)$; Nasal width/intercanthal distance (1.2 \pm 0.0 and $1.2 \pm 0.0)$; Nasal width/Mouth width $(0.8$ and $0.8 \pm 0.1)$; Neoclassical cannons assessed as follows: Nasoaural Canon IV fits $6 \%$ males and $4.5 \%$ females, Naso-occular canon V was the least frequently validated, and fits $2.5 \%$ males and $3 \%$ females, Naso-oral Canon VII was most frequently validated and fits $13.5 \%$ males and $8 \%$ females. Ibibio nose is predominantly platyrrhine. There is no statistically significant sexual dimorphism in nasal length but there is for the other parameters and indices measured and calculated. The Neoclassical canons fit a small fraction of the population and hence cannot be applied in this population. Proportions and ratios derived in this study may be a replacement for absolute values.

Keywords: Nasal anthropometry, Ibibio, neoclassical canons.

Copyright @ 2019: This is an open-access article distributed under the terms of the Creative Commons Attribution license which permits unrestricted use, distribution, and reproduction in any medium for non-commercial use (NonCommercial, or CC-BY-NC) provided the original author and source are credited.

\section{INTRODUCTION}

The nose is the keystone of the face. Its central location makes it an important aesthetic feature, as any anomaly (congenital or acquired), is unlikely to go unnoticed. In addition to the function of breathing, it also helps in defining the racial characteristics of an individual and confers the characteristic of attractiveness to the face [1]. Anthropometry is the science of measurements of body parts as well as proportions of various body parts. Nasal anthropometry is the quantitative measurement of nasal dimensions. It provides normal dimensions that can serve as endpoints for corrective surgeries of craniofacial anomalies or in aesthetic rhinoplasty [1,2] and the difference between a good and a poor outcome in Rhinoplasty can sometimes be measured only in millimeters. Facial measurements were first performed by the Greeks for the purposes of guiding artists in the creation of art. This led to the development of the Nine Neoclassical Canons whose influence formed the foundation of modern facial analysis employed by plastic surgeons for aesthetic surgery on the face [3-5]. Anthropometric dimensions of the Caucasian nose have been extensively studied and values extensively documented $[1,5]$. These have been used as the end point against which all rhinoplasties and nasal reconstructions are compared [6]. With more non-Caucasian persons seeking rhinoplasty, as well as corrective surgery for congenital anomalies on the nose, and the fact that standards of beauty differ from one race to another and several studies detailing nasal parameters among Indians [7], Chinese [8, 9], and African-americans [10] etc, to be significantly different from those of Caucasians, it means that using only Caucasian parameters is not 
tenable in the realization of acceptable results for all patients $[8,11]$. The reconstructed nose needs to be in harmony with the rest of the person's ethnic features [10]. The concept of Ethnicity has evolved over time with definitions of six major ethnicities in the World: Africans, Asians, Latin Americans, and Mediterranean, Middle Eastern and North Europeans [12]. These definitions are inadequate as a large variety and racial mixtures occur with Africans being the most variable race on earth. Nasal characteristics differ from one race to another with the flat, broad nose being ubiquitous among most populations in Africa [13]. In West, South and some parts of Central Africa, most of the features of large noses and thick lips can be found. While in the East and North Africa, thin noses and thin lips approximating Caucasian proportions can be found. Even in Nigeria, such variations can be seen. As such, any planned aesthetic surgery to the nose in this ethnicity may utilize a subset of different aesthetic endpoints to achieve racial harmony. This is one of the reasons that informed the decision to undertake this study. Also, correlating the nasal parameters with the facial proportions has not been measured in many subSaharan ethnic groups. This study, utilizing the Ibibio subset will obtain data on these parameters in the Ibibio population. The operated nose does not stand in isolation and its parts are not viewed independently of each other. It is imperative that the nose and its parts be in proportion with each other and with other facial parameters. Ethnic nose especially African nose rhinoplasty is one of the most complicated and difficult operative procedures performed in rhinoplasty as most ethnic group are different and each requires a different aesthetic endpoint. Even within the same ethnicity, facial characteristics can be perceived differently. Most of these individuals desire nasal refinement/reshaping while preserving their cultural identity. The rhinoplasty surgeon therefore needs to improve the nose without changing them to a different race, and the 'new nose' must be congruous with the rest of the face [14]. Ethnic rhinoplasty therefore focuses on preserving the ethnic qualities of the nose while reshaping it. Earlier attempts at conceptualizing the ideal nose resulted in the introduction of the Neoclassical Canons which has nine (9) parameters with four (4) of these addressing Nasal Aesthetics. These include: canon IV: the ideal nose should be equal in length to the ear length, Canon V: Nose width should be equal to the intercanthal distance, and Canon VII: nose width multiplied by 1.5 should be equal to the width of the mouth [15]. These cannons fit more closely with Caucasian nasal parameters and have been shown not to describe ethnicities like blacks and Asians [8, 16]. In Nigeria, data for Igbos [17], Yorubas, Hausas, Bekwara and Ijaws etc, is available but limited data is available for the Ibibio population on which this study will be carried out. This study will therefore aim to obtain the normal nasal parameters for Ibibios in Nigeria. It will also compare the nasal parameters of males and females to assess for sexual dimorphism and also compare the nasal parameters with the neoclassical canons to generate reference values and proportions that will aid a Surgeon's decision at rhinoplasty in this population.

\section{MATERIALS AND METHODS}

Ethical clearance was obtained from the University of Uyo Teaching Hospital Ethical Committee. This was a cross sectional study involving persons aged 18-60 years, who met the inclusion criteria at the University of Uyo teaching hospital (UUTH), Akwa Ibom State, Nigeria from July 2015 and ended May 2016.Four hundred persons were included in the study. After obtaining informed consent, demographic data was obtained including age, sex, location of residence, tribe of parents and grandparents. Included in the study were persons who were of Ibibio tribe and had parents and grandparents who were also Ibibio (maternally and paternally), persons aged between 18-60 years, persons without congenital facial anomalies to avoid displaced landmarks, persons without history of nasal trauma or surgery and also without any noticeable disfigurement. The parameters assessed included: Nasal length, Nasal width, Ear length, Intercanthal distance and Mouth width using standard landmarks (figure 1). The Proportions calculated were Nasal index, Naso aural proportion, Naso labial proportion, Naso ocular proportion. Data were collected using a semi structured interviewer administered proforma. Measurements were made using digital vernier calipers with precision level of $0.1 \mathrm{~mm}$ and recorded in millimeters. Digital vernier Calipers were used to measure nasal length, width, intercanthal distance, ear length and mouth width. Measurements were all obtained by the same researcher to minimize errors. The subject was seated comfortably on a chair, with the head in the anatomical position. Surface landmarks on the face were located by palpation. Measurements taken included: Nasal length, nose width. Nasal length was measured from the nasion to the subnasale. The nasal width encompassed the distance between the alae (al-al).

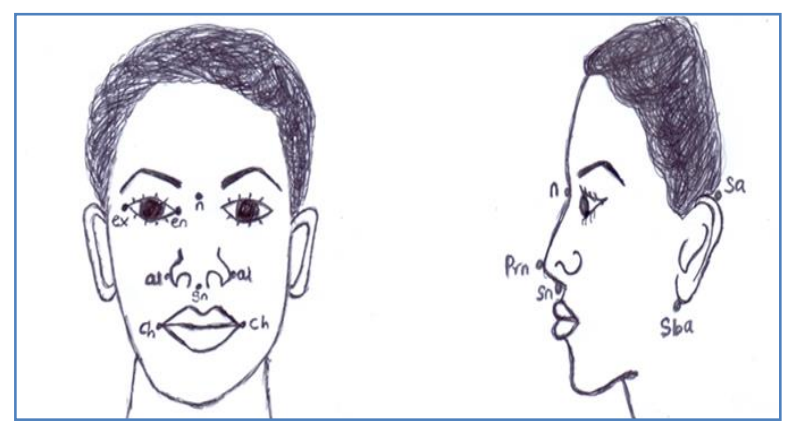

Fig-1: Frontal and lateral views showing the landmarks used in the nasal anthropometry: Alar margin(al), subnasale (sn), nasion (n), glabella(g), medial canthus (en), lateral canthus (ex), oral commissure (ch), Gnathion (gn), zygoma(zy),pronasale(prn), supraaurale(sba), subaurale(sba) 


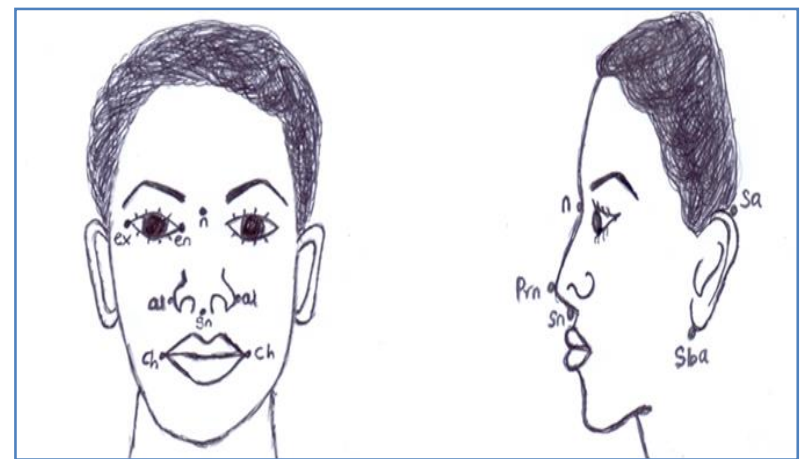

Fig-2: Frontal and lateral views showing the landmarks used in nasal anthropometry: Alar margin(al), subnasale (sn), nasion (n), glabella(g), medial canthus (en), lateral canthus (ex), oral commissure (ch), Gnathion (gn), zygoma(zy)

Nasal parameters measured with these landmarks: nasion-subnasale $(n-s n)=$ Nasal length, cheilon-cheilon (ch-ch) = Mouth width, supraauralesubalare $(s a-s b a)=$ Ear length ,endocanthionendocanthion $($ en-en $)=$ intercanthal distance .
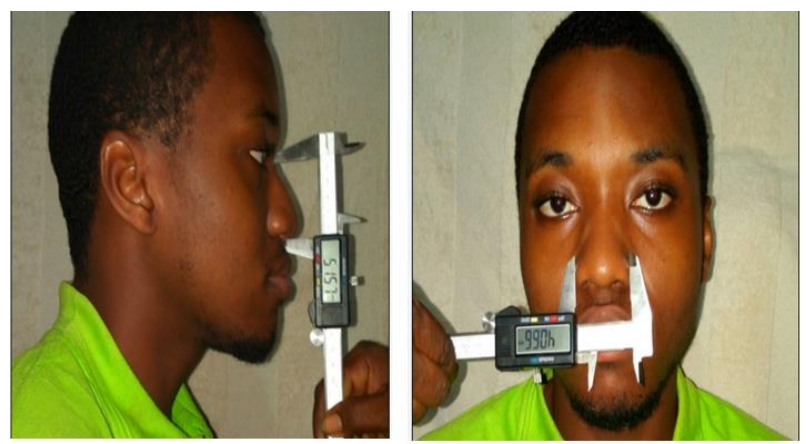

Fig-3: Measurement process illustrating measurement of the nasal length and nasal width using a digital vernier caliper

Data were analyzed using statistical package for social sciences (SPSS) version 20 and results displayed on tables, graphs and charts. A confidence level of $95 \%$ was chosen with 0.05 level of significance. The data were compared to that from other
Nigerian ethnic groups from other studies and that from other races. Independent t-test was used to analyze nasal parameters between males and females while single sample t-test was used to compare the parameters with that of other tribes and races.

\section{LIMITATION OF THE STUDY}

This was a morphometric study requiring specific landmarks. Measurements had to be taken by one investigator as perception of landmarks may differ from person to person. It was sometimes difficult to get an individual to maintain a neutral facial expression through the period of measurement.

The Ibibio are a small tribe when compared to the larger and more populated tribes in Nigeria. Proportions and indices derived in this study may not apply to the other tribes.

\section{RESULTS}

This study utilized morphometric methods to assess different nasal parameters of the Ibibio ethnic group in both sexes. 400 subjects were analyzed; $200(50 \%)$ males and 200(50\%) females. The mean age of subjects was $33 \pm 11$ years. The mean age for males was $32 \pm 11$ years; mean age for females was $33 \pm 11$ years. The age group distribution analyses revealed that majority $(39 \%)$ of the respondents are within the Age group 18-27years (Table 1).

Table-1: Age Group Distribution of the Study

\begin{tabular}{|l|l|l|}
\hline Age groups(yrs) & Frequency (n) & Percent (\%) \\
\hline $\mathbf{1 8 - 2 7}$ & 155 & 38.8 \\
\hline $\mathbf{2 8 - 3 7}$ & 120 & 30.0 \\
\hline $\mathbf{3 8 - 4 7}$ & 78 & 19.5 \\
\hline $\mathbf{4 8 - 6 0}$ & 47 & 11.8 \\
\hline Total & 400 & 100.0 \\
\hline
\end{tabular}

Table-2: Nasal and facial parameters of Ibibios by gender

\begin{tabular}{|l|l|l|l|l|}
\hline Parameter & Males & Females & Pvalue & 95\% CI \\
\hline Nasal Length & $46.4 \pm 1.7$ & $46.1 \pm 1.6$ & 0.123 & $-0.6,0.1$ \\
\hline Nasal Width & $44.05 \pm 1.6$ & $41.2 \pm 1.3$ & 0.000 & $-3.1,-2.5$ \\
\hline Nasal Index & $95.2 \pm 3.2$ & $89.6 \pm 3.4$ & 0.000 & $-6.2,-4.9$ \\
\hline Mouth Width (Ch-Ch)Mm & $55.8 \pm 1.7$ & $52.7 \pm 1.7$ & 0.000 & $-3.7,-2.4$ \\
\hline Ear Length(Sa-Sba) & $57.17 \pm 4.5$ & $56.8 \pm 3.4$ & 0.378 & $-0.5,1.3$ \\
\hline Intercanthal Distance(En-En) & $36.28 \pm 1.2$ & $35.22 \pm 0.9$ & 0.000 & $-1.4,-0.9$ \\
\hline $\begin{array}{l}\text { Nasal Width/Intercanthal Distance(Al-Al/En- } \\
\text { En) }\end{array}$ & $1.2 \pm 0.0$ & $1.2 \pm 0.0$ & 0.000 & $-0.0,-0.0$ \\
\hline Nasal Length/Ear Length Ratio(N-Sn/Sa-Sba) & $0.8 \pm 0.1$ & $0.8 \pm 0.1$ & 0.068 & $-0.1,0.0$ \\
\hline $\begin{array}{l}\text { Nasal Width/Mouth Width Ratio(Al-Al/Ch- } \\
\text { Ch) }\end{array}$ & $0.8 \pm 0.0$ & $0.8 \pm 0.1$ & 0.896 & $-0.0,-0.0$ \\
\hline
\end{tabular}

*all measurements are in $\mathrm{mm}$

Outlines the Nasal parameters in Males and Females of the study population

\section{Nasal length}

The mean nasal length was $46.4 \pm 1.7 \mathrm{~mm}$ for males and $46.1 \pm 1.6 \mathrm{~mm}$ for females. The difference was 
not statistically significant at $95 \%$ confidence interval, showing that there was no sexual dimorphism in nasal lengths for this study population (Table 2).

\section{Nasal width}

The mean nasal width for this study population was $44.05 \pm 1.6 \mathrm{~mm}$ for males and $41.2 \pm 1.3 \mathrm{mmfor}$ females. The difference was statistically significant. A mean difference of $2.83 \mathrm{~mm}$, with males having a significantly higher $(\mathrm{p}<0.05)$ value of nasal width than females (Table 2).

\section{Nasal index}

This is the ratio of nasal width to nasal length multiplied by 100 . The mean nasal index was $95.2 \pm 3.2$ for Ibibio males and $89.6 \pm 3.4$ for Ibibio females showing statistically significant $(\mathrm{p}<0.05)$ sexual dimorphism and a mean difference of 5.6mm. $97 \%$ (193) males had platyrrhine nose type (nasal index $>85$ ), while $3 \%$ (7) males had mesorrhine nose (nasal index 70-84.9).

$91 \%$ (181) females had platyrrhine nose type while $9 \%$ (19) had mesorrhine nose type. More females than males had mesorrhine nose type. None of the subjects $(0 \%)$ had leptorrhine nose (nasal index < 69.9) was not found in any of the study population (Table 2).

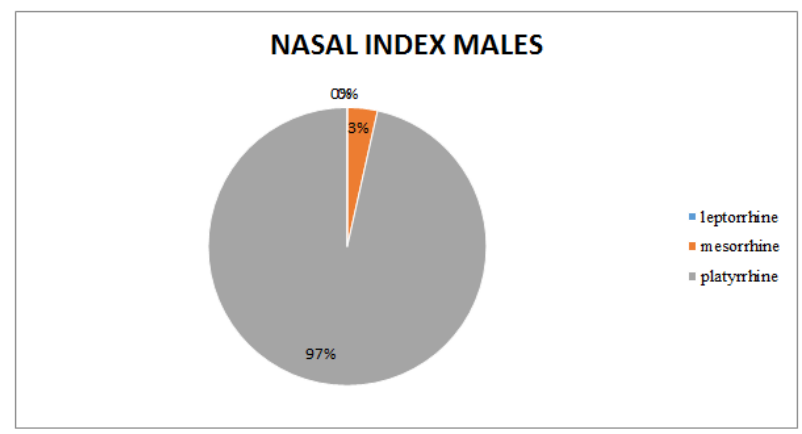

Fig-3: The distribution of nose types among the males in the study population based on nasal index: $97 \%(193)$ have Platyrrhine nose types, 3 \% ( 7) have Mesorrhine nose types, 0 \% ( 0 ) Leptorrhine nose types

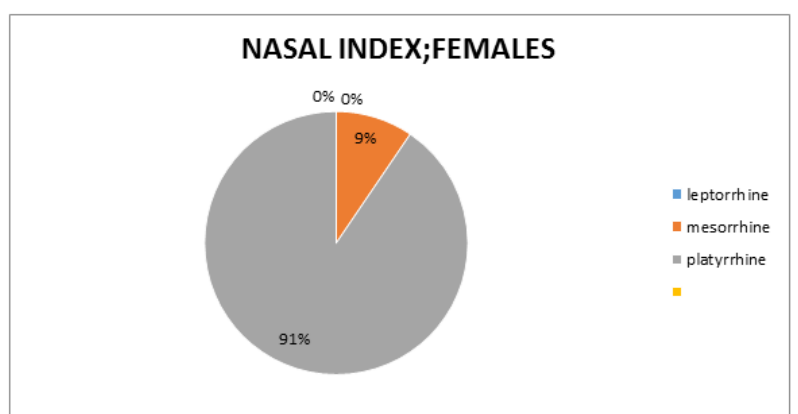

Fig-4: The distribution of nose types among Ibibio females in the study population based on nasal index. $91 \%$ ( 181) have

Platyrrhine nose types, $7 \%$ ( 19) have Mesorrhine nose types. 0 \% (0) has Leptorrhine nose types

\section{Nasal proportions}

Naso aural proportion (canon IV)

In Ibibio males, average ear length was $57.17 \pm 5.5$. $6 \%$ (12) had nasal length (NL) equal to the ear length (NL=EL), 92\% (184) had nasal length less than ear length (NL<EL), while $2 \%$ (4) had nasal length greater than ear length (NL $>E L)$. Average ratio of nasal length to ear length was $0.8 \pm 0.5$ (Table 2).

In Ibibio females, average ear length was $56.8 \pm 3.4 \mathrm{~mm} .93 .5 \%(187)$ had nasal length less than ear length( NL<EL), 4.5\%(9) had nasal length equal to ear length(NL=E) while 2\%(4) had nasal length greater than ear length (NL>EL). Average ratio of nasal length to ear length was also $0.8(\mathrm{p}<0.05)$ (Table 2$)$.

\section{Orbitonasal proportion (canon V)}

Neoclassical canon $\mathrm{V}$ specifies that nasal width equals intercanthal distance. In this study, average ratio of nasal width to intercanthal distance was 1.2. $97.5 \%$ (195) had nasal width greater than intercanthal distance, $2.5 \%$ ( 5) had nasal width equal to intercanthal distance. While none of the males had nasal width less than intercanthal distance.

In females, average ratio was also 1.2. 97\% (194) had nasal width greater than intercanthal distance, $3 \%$ (6) had nasal width equal to intercanthal distance and none had nasal width less than intercanthal distance (Table 2).

\section{Naso-oral proportion (canon VII)}

Mouth width among males of this study population was $55.8 \pm 1.7 \mathrm{~mm}$.Neoclassical canon VII states that nasal width $\times 1.5$ equals oral width. $86.5 \%$ ( 173) males had mouth width less than 1.5 times mouth width. $13.5 \%$ (27) had mouth width equal to 1.5 times mouth width but none had mouth width greater than 1.5 times mouth width. Average ratio of nasal width to mouth width was 0.8 . (Table 2).

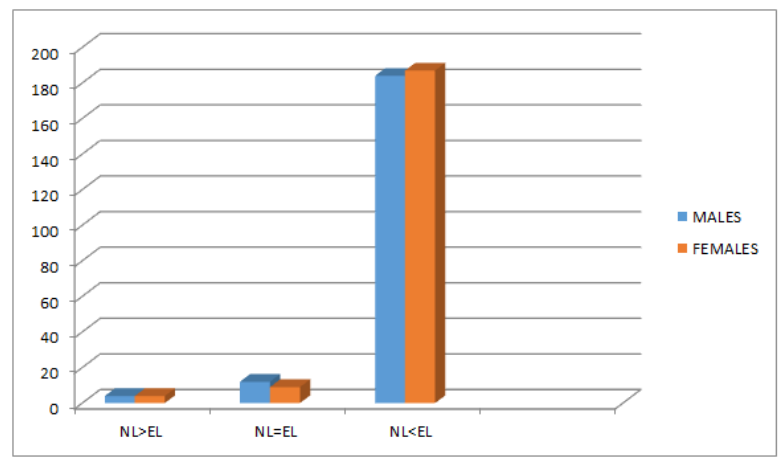

Fig-5: Chart of relationship with Naso aural Canon (Canon Iv). $\mathrm{NL}=$ nasal length, $\mathrm{EL}=$ ear length

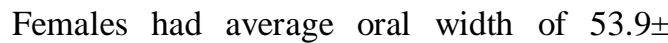
$4.5 \mathrm{~mm}$ which was significantly less than the males $(\mathrm{p}<0.05) .91 \%$ (182) had mouth width less than 1.5 times nasal width, $8 \%$ (16) had mouth width equal to 
1.5 times nasal width and $1 \%$ (2) had mouth width greater than 1.5 times nasal width. Nasal width to oral width ratio was 0.8 . All values were statistically significant $(\mathrm{p}<0.05)$ (Table 2$)$. The most frequently validated neoclassical canon in this population was the naso-oral canon, $13.5 \%$ in males and $8 \%$ in females (Table 4).

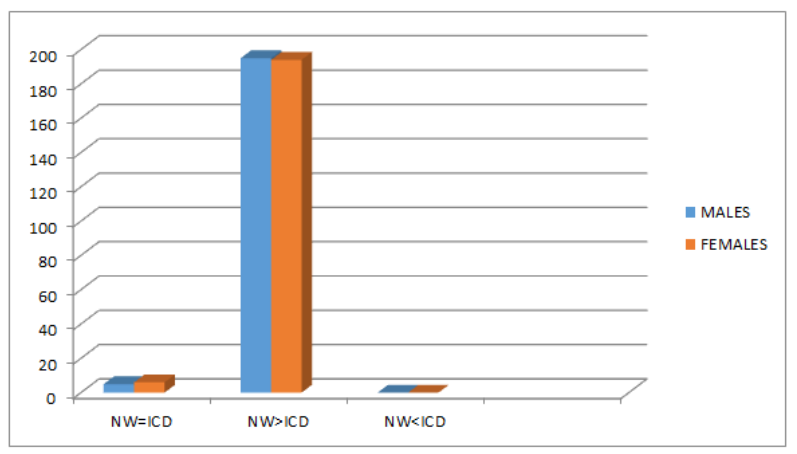

Fig-6: Chart of Relationship with Orbito Nasal Canon (Canon V). NW=nasal width

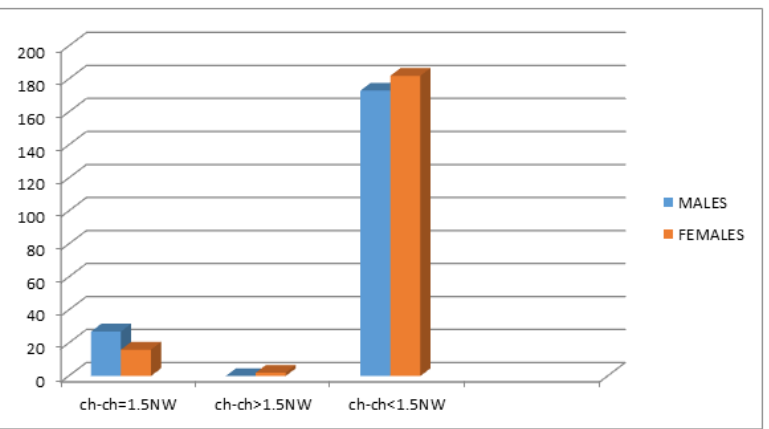

Fig-7: Chart Of Relationship with Naso Oral Canon (Canon Vii), ch-ch= mouth width, $\mathrm{NW}=$ nasal width

\section{DISCUSSION}

The mean nasal length in this study at $46.4 \mathrm{~mm}$ and $46.1 \mathrm{~mm}$ in males and females respectively showed no statistically significant sexual dimorphism (Table 2). These values were similar to the Isoko and Omoku males who had nasal lengths of $46.0 \mathrm{~mm}$ and $46.6 \mathrm{~mm}$ respectively. Eliakim et al. obtained nasal lengths of $48.1 \mathrm{~mm}$ and $44.7 \mathrm{~mm}$ in Ibibio males and females respectively [20]. Reason for the differences with this study could be intra ethnic variation which has been observed in other tribes. Differences have been observed even in other populations studied, even though these belong to the same tribe. Garandawa et al. obtained $46.2 \mathrm{~mm}$ nasal length for Yoruba males and $49.7 \mathrm{~mm}$ nasal length for Hausa males in contrast to $42.6 \mathrm{~mm}$ (Yoruba males) and $56.7 \mathrm{~mm}$ (Hausa males) obtained by Anas et al. on Yoruba males [19, 21].

Nasal length was greater than that in males and females from Ijaw, Urhobo, Itsekiri, Bekwarra and Yoruba $(40.8 \mathrm{~mm}$ v $38.9 \mathrm{~mm}, 43.67 \mathrm{~mm} \mathrm{v} 41.51 \mathrm{~mm}$, $42.02 \mathrm{~mm} v 40.83 \mathrm{~mm}, 42.4 \mathrm{~mm}$ v $42.8 \mathrm{~mm}, 41.8 \mathrm{~mm} \mathrm{v}$ $42.5 \mathrm{~mm}$ ) [22-24] it was however less than Nasal lengths of the Igbo and Hausa males $(48.7 \mathrm{~mm}$ and
$56.7 \mathrm{~mm})[21]$. Nasal length in Hausa females $(54 \mathrm{~mm} \pm$ $4.8 \mathrm{~mm})$ was greater than the study population $(46.1 \mathrm{~mm})[22]$. A difference of $3-8 \mathrm{~mm}$ was noted in female nasal lengths between the study population and the females of Isoko, Omoku, Ijaw, Bekwarra and Itsekiri [25]. All the above ethnic groups showed sexual dimorphism in nasal length unlike in the study population.

These ethnic groups are located in geographical areas close to the Ibibio. This suggests that climate may not play a role in the shaping of nasal and facial features in these populations. Differences may be due to different ancestry and also, the measurement process may account for the differences. Some researchers measure nasal length from the nasion to the pronasale and some from the nasion to the subnasale. This is not commonly stated in the studies. In this study, measurement was made from the nasion to the subnasale. There was statistically significant difference between Ibibio male and female nasal lengths $(46.4 \mathrm{v} 46.1 \mathrm{~mm})$ and males and females of African American(52.4 v 49.3), North American $(53 \mathrm{~mm}$ v $48.9 \mathrm{~mm})$, Italians $(56.2 \mathrm{~mm}$ v $52.1 \mathrm{~mm})$ and Japanese $(56.9 \mathrm{~mm}$ v $53.3 \mathrm{~mm})$ descent[2]. Difference in genetics and ancestry may account for these differences. Even African Americans have extensive interracial mixing and so values are different from that of the subjects in this study.

The nasal width is one of the parameters most persons of Black origin seek to change in rhinoplasty. In the study population, this was found to be $44.05 \mathrm{~mm}$ in males and $41.2 \mathrm{~mm}$ in females $(\mathrm{p}<0.05)$. These values were greater than in the Isoko, Omoku, Ijaw, Urhobo, Itsekiri males and females with $42 \mathrm{~mm} \mathrm{v} 38.7 \mathrm{~mm}$, $40.1 \mathrm{~mm}$ v $39.3 \mathrm{~mm}, 40.6 \mathrm{~mm}$ v $37.9 \mathrm{~mm}, 39.15 \mathrm{~mm}$ v $36.83 \mathrm{~mm}, 38.6 \mathrm{~mm} \mathrm{v} 36.28 \mathrm{~mm}$ respectively[24, 22, 26]. The nasal width of Ibibio males and females is wider than that of African Americans, North American whites, Italians, Japanese and Egyptians at $43.5 \mathrm{~mm} \mathrm{v}$ $40 \mathrm{~mm}, 34.7 \mathrm{~mm} \quad \mathrm{v} 31.4 \mathrm{~mm}, 32.1 \mathrm{~mm}$ v $29.5 \mathrm{~mm}$, $38.2 \mathrm{~mm}$ v $37.1 \mathrm{~mm}$ and $32.4 \mathrm{~mm}$ v $29.3 \mathrm{~mm}$ respectively. All were statistically significant and showed sexual dimorphism [2].

Mean nasal indices for males and females was 95.2+/- 3.2 and 89.6+/- 3.4 respectively, and showed statistically significant sexual dimorphism (Table 2). $96.5 \%$ (193) of males and 90.5\% (181) of females had platyrrhine nasal types (Figure 2 and figure 3 ). This was less than that for Yoruba (100.4)[27] and Igbo (107.6)[22] males and females who also predominantly have platyrrhine nose types. It was greater than that of Hausas (70.7)[19] who have predominantly mesorrhine nose types among males and leptorrhine nose types among females due to longer and narrower noses. It was greater than that of the Isoko (92.3)[26], Omoku (86), Urhobo (89.7)[24], and Itsekiri (91.9). Mean nasal 
index in males was more than that in the African American males who had 83.8[11]. The female nasal index was 89.6, showing that females in the study population were predominantly of Platyrrhine nose type. This was less than females from Ijaw (97.8)[20],
Omoku (90.1), Yoruba (95.5)[28], Igbo (98.9) [23] but more than Isoko (89.5), Urhobo (88.7), Itsekiri (88.6), and Hausa (67.5). Caucasian females had indices of 64.4[2] while Korean females had 89.6[8], both significantly less than the subjects of this study.

Table-3: Comparison of Ibibio Nasal Parameters with Other Races

\begin{tabular}{|l|l|l|l|l|l|l|l|}
\hline \multirow{2}{*}{ PARAMETERS } & \multicolumn{2}{|l|}{ IBIBIO } & \multicolumn{2}{l|}{ African Americans } & North American whites & Koreans \\
\cline { 2 - 8 } & MALES & FEMALES & Males & Females & Males & Females & Females \\
\hline Nasal length & 46.4 & 46.2 & 52.4 & 49.3 & 53.0 & 48.9 & 51.8 \\
\hline Nasal width & 44.2 & 41.4 & 41.4 & 43.5 & 34.7 & 31.4 & 35.5 \\
\hline Nasal index & 95.2 & 89.6 & 83.8 & 81.7 & 65.8 & 64.4 & 68.5 \\
\hline
\end{tabular}

*p values from one sample t test.

\section{Validation of Neoclassical Nasal Canons}

Nasal length to ear length proportion as stated by the universally accepted neoclassical canon IV states that the nose length equals the ear length. This was validated in only $6 \%$ (12) of the Ibibio males and $4.5 \%$ (9) of the females (Table 4). Most of the subjects had nasal length less than ear length; $92 \%$ (184) of males and 93.5\% (187) females (Figure 4), (Table 4). The ratio of nasal length to ear length in this population was approximately 0.8 in both males and females (Table 2). This may be substituted for this population instead of the neoclassical canons in this population.

Table-4: Relationship of the Nasofacial proportions in Ibibios with caucasian neoclassical canons

\begin{tabular}{|l|l|l|}
\hline \multirow{2}{*}{ Canons } & \multicolumn{2}{|l|}{ \% Study Population (N)S } \\
\cline { 2 - 3 } & Males & Females \\
\hline CANON IV(naso aural) \\
\hline n-sn = Sa-Sba & $2 \%(4)$ & $4.5 \%(9)$ \\
n-sn > Sa-Sba & $6 \%(12)$ & $2 \%(4)$ \\
n-sn < Sa-Sba & $92 \%(184)$ & $93.5 \%(187)$ \\
\hline CANON V(orbitonasal) \\
\hline al-al = en-en & $2.5 \%(5)$ & $3 \%(6)$ \\
al-al > en-en & $97.5 \%(195)$ & $97 \%(194)$ \\
al-al < en-en & $0 \%(0)$ & $0 \%(0)$ \\
\hline CANON VII(naso oral) \\
\hline Ch-ch = 1.5al-al & $13.5 \%(27)$ & $8 \%(16)$ \\
Ch-ch > 1.5 al-al & $0 \%(0)$ & $1 \%(2)$ \\
Ch-ch < 1.5 al-al & $86.5 \%(173)$ & $91 \%(182)$ \\
\hline
\end{tabular}

The Nasal width should equal the intercanthal distance in neoclassical cannon $\mathrm{V}$ (orbitonasal canon). In this study,most subjects had nasal width greater than intercanthal distance; $97.5 \%$ ( 195) of males and $97 \%$ (194) of females (Table 4). None had nasal width less than intercanthal distance. This was the most infrequently validated neoclassical canon in the Ibibio population. (Figure 6) This correlates with findings among African Americans where only 3\% had the orbitonasal relationship stipulated by the neo classical canon. Among the Arabs however, it was the most frequently validated canon in females, with $33.3 \%$ having intercanthal distances equal to nasal widths [29]. $40.8 \%$ of North American whites and $35.4 \%$ of Chinese show this relationship [6]. These differences may be attributed to the wider nose in the Ibibio and African Americans than the other races and ethnicities. The average ratio of the intercanthal distance to the nasal width was $1: 1.2 \mathrm{~mm}$ in both sexes (Table 2) and was significant using the independent t-test $(\mathrm{p}<0.05)$. This was also correlated among African American females who had a 1:1.2 ratio of intercanthal distance to alar width [20]. The Neoclassical Canon VII (naso oral canon) states that nasal width multiplied by 1.5 should equal oral width. In this study population, this was validated in $13.5 \%$ (27) males and $8 \%$ (16) females (Table 4). 86.5\% (173) males and 91\% (182) females had mouth width less than 1.5 ala width (Table 4). This correlated with that of African American females where $87 \%$ had nasal width $\times 1.5$ greater than oral width [30]. This was the most frequently validated canon in both sexes in this study (Figure 7). The ratio of the ala width to the mouth width was 0.8 in both sexes (Table 2). This ratio may be preferable in determining nasal length and width instead of using the neoclassical proportion in this population. These values may be substituted in the study population instead of the classical values because the greater proportion of this study subjects did not fit into any of the nasal related Neoclassical canons showing that it is not correct to use these parameters in this group of patients when planning rhinoplasty or other nasal reconstructive surgery. The results are likely to be incongruous with the ethnic appearance of the individual. 


\section{CONCLUSION}

This study has been able to evaluate nasal parameters that were not previously documented in the Ibibio ethnic group of Southern Nigeria. The results show that the majority have a platyrrhine nasal type. There is also a 1:1.2 relationship between the intercanthal distance and nasal width as well as a 0.8 ratio between the nasal length and the ear length regardless of sex. Nose width: oral width ratio also exhibited a 0.8 ratio. All nasal parameters except nasal length showed sexual dimorphism and differed significantly from other tribes and races. These parameters provide important data to guide forensic medicine, prosthesis fashioning and plastic surgeons in doing rhinoplasty and nasal reconstruction.

\section{RECOMMENDATION}

The nasal parameters measured can be put in consideration during ethnic rhinoplasty and nasal reconstructive surgery in the Ibibio. These data can also be used for purposes of creating nasal prostheses for persons who have lost their nose to ablative surgery and are not candidates for rigorous reconstructive procedures.

The nasal proportions elucidated in this study may not be applicable to other ethnicities and hence such studies may need to be done to obtain ratios which may replace use of absolute values in planning rhinoplasty and reconstructive surgery for the various populations.

\section{REFERENCES}

1. Chatrath, P., De Cordova, J., Nouraei, S. R., Ahmed, J., \& Saleh, H. A. (2007). Objective assessment of facial asymmetry in rhinoplasty patients. Archives of facial plastic surgery, 9(3), 184-187.

2. Farkas, L. G., Katic, M. J., \& Forrest, C. R. (2005). International anthropometric study of facial morphology in various ethnic groups/races. Journal of Craniofacial Surgery, 16(4), 615-646.

3. Harzika, P., Nayak, D.R., Balakrishna, G. (2007). Structure of the external nose in: Textbook of ENT and Head and Neck Surgery.1st ed .CBS publisher, New Delhi: 49-250.

4. Merriam Webster's Dictionary. (2009). 'Encyclopedia Brittanica' ultimate reference suite, Chicago. Encyclopedia Brittanica.

5. Farkas, L. G., Bryson, W., \& Klotz, J. (1980). Is photogrammetry of the face reliable?. Plastic and Reconstructive surgery, 66(3), 346-355.

6. Farkas, L. G., Kolar, J. C., \& Munro, I. R. (1986). Geography of the nose: a morphometric study. Aesthetic plastic surgery, 10(1), 191-223.

7. Khandekar, B., Srinivasan, S., Mokal, N., \& Thatte, M. R. (2005). Anthropometric analysis of lip-nose complex in Indian population.
8. Choe, K. S., Yalamanchili, H. R., Litner, J. A., Sclafani, A. P., \& Quatela, V. C. (2006). The Korean American woman's nose: an in-depth nasal photogrammatic analysis. Archives of facial plastic surgery, 8(5), 319-323.

9. Teck, S. R. S., Smith, J. D., \& Chan, A. S. (2000). Comparison of the aesthetic facial proportions of southern Chinese and white women. Archives of facial plastic surgery, 2(2), 113-120.

10. Ofodile, F.A., Bokhari, F. (1995). The African American Nose: part II. Ann Plast Surg, 34:123129.

11. Patil, S. B., Kale, S. M., Jaiswal, S., Khare, N., \& Math, M. (2011). The average Indian female nose. Aesthetic plastic surgery, 35(6), 1036-1042.

12. Gilbert, J., Nolst, T. (2003). Considerations in Ethnic Rhinoplasty. Facial Plast Surg, 19(3): 239246.

13. Romo Iii, T., \& Abraham, M. T. (2003). The ethnic nose. Facial plastic surgery, 19(03), 269-278.

14. Begg, R. J., \& Harkness, M. (1995). A lateral cephalometric analysis of the adult nose. Journal of oral and maxillofacial surgery, 53(11), 1268-1274.

15. Neger, M. (1959). A quantitative method for the evaluation of the soft-tissue facial profile. American journal of Orthodontics, 45(10), 738-751.

16. Wisth, P. J., \& Böe, O. E. (1975). The reliability of cephalometric soft tissue measurements. Archives of oral biology, 20(9), 595-599.

17. Akpa, A. O. C., Ugwu, C., Maliki, A. O., \& Maliki, S. O. (2003). Morphometric study of the nasal parameters in Nigerian Igbos. Journal of Experimental and clinical anatomy, 2(2), 24-25.

18. Oladipo, G., Hakeem, F., Yemi, S. (2009). The study of Nasal Parameters among the yorubas of Nigeria. Internet journal of biological anthroplology, 3(2)..

19. Anas, I. Y. (2010). Nasal Index of the Hausa Ethnic Group, a study conducted on students at Bayero University Kano. Journal of Medicine in the Tropics, 12(1).

20. Eliakim-Ikechukwu, C., Iro, C. M., Ihentuge, C. J., \& Bassey, T. E. (2013). Nasal parameters of Ibibio and Yakurr ethnic groups of south-south Nigeria. Journal of pharmacy and Biological Sciences, 5 (6), 23-26.

21. Garandawa, H.I., Nwaogu, O.G.B., Oluwatosin, O.M. (2009).The internet journal of otorhinolaryngology.

22. Olotu, J., Erojje, Ahmed., Oladipo, G., Edibamode, E.(2009). The internet journal of biological anthropology.

23. Anas, I.Y., Aleh M.S. Anthropometric comparison o nasal indices between husa and yoruba ethnic groups in nigeria. Journal of scientific research and reports 2014,3 (3): 437-444.

24. Anibor, E., Etetafia, M. O., Eboh, D. E., \& Akpobasaha, O. (2011). Anthropometric study of 
the nasal parameters of the Isokos in Delta State of Nigeria. Ann Biol Res, 2(6), 408-413.

25. Oladipo, G. S., Udoaka, A. I., Afolabi, E. O., \& Bob-Manuel, I. (2009). Nasal Parameters of Itsekiris and Urhobos of Nigeria. International Journal of Biologica Anthropology, 3(1).

26. Esomonu, U. G., Ude, R. A., Lukpata, P. U., \& Nandi, E. M. (2013). Anthropometric study of the nasal index of Bekwara ethnic group of cross river state, Nigeria. International Research Journal of Applied and Basic Sciences, 5(10), 1262-1265.

27. Emelike, N. V., Garba, S. H., Dalori, B. M., \& Numan, A. I. (2012). Anthropometric study of LipNose complex in adult Igbo's resident in
Maiduguri.Journal of Dental and Medical Sciences (JDMS), 1(3), 29-31.

28. Joy, O., Ahmed, E., Gabriel, O., \& Ezon-Ebidor, E. (2009). Anthropometric study of the facial and nasal length of adult Igbo ethnic group in Nigeria. Internet Journal of Biological Anthropology, 2(2).

29. Al-Sebaei, M. O. (2015). The validity of three neoclassical facial canons in young adults originating from the Arabian Peninsula. Head \& face medicine, 11(1), 4.

30. Porter, J. P., \& Olson, K. L. (2001). Anthropometric facial analysis of the African American woman. Archives of facial plastic surgery, 3(3), 191-197. 